\title{
ƯớC TÍNH ẢNH HƯỞNG CỦA QUY HOẠCH SỬ DỤNG ĐẤT TRÊN GIÁ TR!̣ ĐẤT, THỬ NGHIỆM CHO KHU VỤ̉C ĐẤT Ở TRÊN ĐỊA BÀN TỈNH QUẢNG NINH
}

\author{
NGUYẼ̃N PHI SƠN, NGUYẼ̃N THANH THỦY, NGUYẼ̃N TH!̣ THANH HƯONG
}

Viện Khoa học Đo đạc và Bản đồ

\section{Tóm tắt:}

Bài báo đề cập đến phưong pháp thành lập bản đồ giá trị đất dựa trên lý thuyết Hedonic và công nghệ GIS, tù đó có thể dụ báo được sụ biến động của giá trị đất khi thay đổi các yếu tố ảnh huởng. Quy hoạch sủ dụng đất là một trong các yếu tố hình thành giá trị đất trong tương lai. Viêc dụ báo được tác động của quy hoạch sủ dụng đất đến xu thế biến động giá trị đất là cần thiết, phuơng pháp xác định giá trị đất dựa trên kỹ thuật máy tính và GIS có thể giải quyết được vấn đề này. Trong bài báo đã thực nghiệm cho khu vục đất ở trên địa bàn tỉnh Quảng Ninh.

\section{Cơ sở tiếp cận xây dựng vùng giá trị đất}

\subsection{Giá trị đất ở Việt Nam}

Đất đai là tài sản, hàng hóa đặc biệt. Trong quá trình sử dụng về cơ bản không bị hao mòn, mà nhiều trường hợp qua sử dụng giá trị của đất lại tăng lên. Giá trị đất được giải thích dưới nhiều quan điểm, nhưng quan điểm đất đai là tài sản, là hàng hóa đã tạo cơ sở tiếp cận trong định giá đất. Đất ở là một lọai hàng hóa được trao đổi và mua bán phổ biến trên thị trường. Hàng hóa có hai thuộc tính là giá trị sử dụng và giá trị. Giá trị sử dụng của hàng hóa được hiểu là công dụng của hàng hóa thỏa mãn nhu cầu nào đó của con người. Giá trị của hàng hóa là lượng lao động xã hội của người sản xuất hàng hóa kết tinh trong hàng hóa. Vậy, xét dưới góc độ hàng hóa, các yếu tố nào làm cho đất đai có giá trị?. Đó chính là tất cả các tính chất tự nhiên vốn có (vị trí, chất lượng) kết hợp với các tác động của con người nhằm cải tạo và sử dụng đã tạo ra giá trị khác nhau của mỗi vị trí đất. Hoàng Hữu Phê và Patrick Wakely (2000) đã coi các tính chất và tác động đó chính là vị thế và chất lượng của đất. Theo A. Myrick Freeman (2003) có hai tiếp cận chính trong việc đo lường giá trị kinh tế của bất động sản là Lý thuyết Tô kinh tế (Theory of Rents) và Lý thuyết Hưởng thụ (Hedonic theory). Lý thuyết Hedonic cho rằng giá trị hay giá trị sử dụng được xác định thông qua việc phân tích các thuộc tính và lượng hóa thuộc tính của đất đai. Từ các lý thuyết và quan điểm trên, chúng ta có thể ước tính được giá trị của tài sản - hàng hóa "đất đai" thông qua quy luật của chuỗi số liệu thống kê nhằm hình thành hàm toán học về giá trị đất, từ đó kết hợp với các ứng dụng của công nghệ GIS trong phân tích không gian, định lượng thuộc tính để hoàn chỉnh quy trình định lượng hóa giá trị đất và biểu diễn bằng mô hình bản đồ (Alicia E. Porcar Lahoz, 2007).

Mỗi đơn vị đất đai phân bố trên lãnh thổ đều có thuộc tính nội tại khác nhau và chịu tác động không giống nhau bởi các yếu tố bên ngoài, kể cả cùng mục đích sử dụng. Tuy nhiên, khi xem xét giá trị bằng tiền tệ trong một khoảng giá nhất định tại một thời điểm nhất định chúng ta sẽ nhận được một số thửa đất có tính chất tương đồng nhau và đó là tiền đề cho hình thành vùng giá trị đất. Xây dựng vùng giá trị đất là quá trình đánh giá mức độ tiềm năng của một vị trí, định lượng hóa vị thế và chất lượngcủa đất đai thông qua đơn vị tiền tệ tại một thời điểm chính là giá đất giao dịch bình thường. Mỗi thửa đất hay đơn vị đất đều có một giá trị nhất định, giá trị thửa đất không thay đổi nếu như các yếu tố hình thành nên giá trị thửa đất không thay đổi [Mehmet Tорси. 2009; Vevin S. Ardiwijaya. 2006]. 
Tuy nhiên, khi xét tới các thuộc tính cá biệt (hướng, diện tích, hình dạng thửa, mặt tiền, tỷ lệ rộng/dài, số lượng cạnh thửa...) của mỗi thửa đất, thì các thửa đất nằm trong một vùng giá trị sẽ có giá trị khác nhau. Xuất phát từ luận điểm trên, khái niệm "giá trị danh nghĩa" được hiểu là giá trị của khu vực đất không tính đến các yếu tố cá biệt của thửa đất riêng lẻ. Giá trị danh nghĩa tồn tại khách quan và vùng giá trị đất thì gắn liền với khái niệm "giá trị danh nghĩa", vùng giá trị đất chỉ được xây dựng trên nền tảng của giá trị danh nghĩa chứ không phải là giá thực tế của thửa khi mua bán, chuyển nhượng [Nguyễn Phi Son. 2015]. Trong nghiên cứu của bài báo này, vùng giá trị đất sẽ được hiểu là vùng giá trị đất danh nghĩa.

Vùng giá trị đất là khái niệm thuộc phạm trù kinh tế đất, đã được nhiều nước trên thế giới nghiên cứu và ứng dụng trong các bài toán liên quan đến quy hoạch, đánh giá tiềm năng khu vực, dự báo kinh tế và định giá đất, đặc biệt là yếu tố hỗ trợ cho các quy hoạch kinh tế xã hội khác. Tùy thuộc vào chế độ sử dụng đất đai của mỗi quốc gia mà phương pháp hình thành vùng giá trị cũng khác nhau. Ở Việt Nam, khái niệm vùng giá trị đã được đề cập đến trong những năm gần đây, một số nghiên cứu về lý thuyết, cách tiếp cận và đưa ra những quan điểm làm sáng tỏ khái niệm giá trị đất, đặc biệt giá trị đất được hiểu là giá trị quyền sử dụng đất. Trong kinh tế đất, vùng giá trị có vai trò quan trọng trong định hướng các bài toán kinh tế, giải quyết các mối quan hệ cơ bản trong định giá bất động sản và điều quan trọng đó là tạo nền tảng cho việc định giá đất hàng loạt.

\subsection{Lụa chọn lý thuyết hưởng thu (Hedonic) là cơ sở hình thành vùng giá trị đất}

Theo Triplett (1986) khung lý thuyết về "hưởng thụ" bao gồm lý thuyết chung về Hedonic (Hedonictheory) và mô hình giá hưởng thụ (Hedonic price Model) được phát triển và sử dụng trong nghiên cứu chỉ số về giá cả thị trường [Haripriya Gundimeda. 2000]. Trong kinh tế học, hồi quy hưởng thụ hay lý thuyết nhu cầu hưởng thụ là một phương pháp ưu tiên đề xuất khi ước đoán nhu cầu hoặc giá trị của hàng hóa. Việc phân tích các yếu tố ảnh hưởng được thực hiện theo từng thành phần, từ đó xây dựng mô hình lượng hóa tác động của chúng tới việc hình thành giá trị hàng hóa, tài sản. Mô hình hưởng thụ đi kèm với thuật giải hồi quy được sử dụng phổ biến để phân phân tích tương quan giữa các thành phần, đặc điểm của đối tượng được định giá với giá trị của nó. Mặc dù, nhiều mô hình tổng quát, nhưng mô hình kết hợp "Hedonic Regresion" là mô hình hiệu quả nhất trong tạo lập hàm giá trị [Haripriya Gundimeda. 2005, Marko Kryvobokov 2006]. Các mô hình hưởng thụ có thể không tuyến tính, các biến tương quan và hàm phụ thuộc có thể tuân theo một quy luật gần đúng nào đó mà bắt buộc chúng ta phải tìm các thuật giải tối ưu nhất để xấp xỉ hóa quan hệ này. Giá trị của hàng hóa thay đổi là do ảnh hưởng của việc điều chỉnh chất lượng tác động hay sự thay thế các thuộc tính tác động, làm cho giá trị hàng hóa thay đổi. Hàng hóa "đất đai" cũng nằm trong cơ chế đó. Người mua sẵn sàng trả giá cao hơn cho các tài sản có môi trường tốt, vị trí tốt và khả năng sinh lợi cao. Phương trình hồi quy hưởng thụ được sử dụng để xác định mối quan hệ giữa các thuộc tính (hoặc tập hợp các thuộc tính) riêng biệt với giá ước tính giá của tài sản đó trên thị trường. Bản chất của việc áp dụng phương pháp xử lý hồi quy hưởng thụ cho hàng hóa đất đai là xác lập quy luật (hàm giá trị) thông qua chuỗi số liệu thống kê nhận được từ các thửa đất đã có giao dịch theo đúng bản chất thị trường [Vevin S. Ardiwijaya. 2006].

Việc lựa chọn, định lượng và không gian hóa các yếu tố tác động tới giá trị đất là tiền đề cho việc sử dụng GIS phân tích mối tương quan giữa các yếu tố hình thành và giá trị đất. Nhiều tác giả Charles A. Calhoun. 2010, Chin Chui Vui. 2006, Abdul Hamid. 2008, Alicia E. Porcar Lahoz. 2007, khi nghiên cứu các ứng dụng của lý thuyết hưởng thụ trong định lượng giá trị đất đã chỉ ra, giá trị của thửa đất chi phối một cách có quy luật bởi các đặc điểm vốn có mà nó như: các yếu tố riêng của thửa đất $\left(s_{1}, s_{2}, s_{3} \ldots\right)$, các yếu tố tự nhiên - môi trường $\left(n_{1}, n_{2}, n_{3} \ldots\right)$, các yếu tố kinh 
tế - xã hội $\left(e_{1}, e_{2}, e_{3} \ldots\right)$, các yếu tố về pháp lý $\left(l_{1}, l_{2}, l_{3} \ldots\right)$. Như phân tích ở trên, vùng giá trị đất phải được hình thành dựa trên khái niệm "giá trị danh nghĩa", vì vậy giá trị của đất $(V)$ được định lượng thông qua hàm (1):

$$
V=f\left(n_{1}, n_{2}, n_{3}, \ldots n_{j} ; e_{1}, e_{2}, e_{3}, \ldots e_{j} ; l_{1}, l_{2},\right.
$$$$
\left.l_{3}, \ldots l_{j}\right) \text {, }
$$

Khi thực hiện quy hoạch, đồng nghĩa với việc các biến $n_{j}, e_{j}, l_{j}$ thay đổi và tương ứng làm cho $V$ thay đổi, đây là cơ sở cho việc dự báo giá trị đất $(V)$ tại một thời điểm trong tương lai theo lộ trình của kế hoạch sử dụng đất hàng năm.

Hàm giá trị đất " $f$ " được thiết lập từ thuật giải hồi quy, dựa trên bộ số liệu mẫu là thông tin về thửa đất có giao dịch mua bán, chuyển nhượng, đấu giá QSDĐ. Đối với Việt Nam thông tin chính xác về các giao dịch mua bán, chuyển nhượng là rất khó thu thập, vì vậy giá đất tin cậy nhất là thông qua đấu giá quyền sử dụng đất thành công tại địa phương. Thông thường các thửa đất đấu giá đều có kích thước tiêu chuẩn khoảng $100 \mathrm{~m}^{2}$ (rộng $5 \mathrm{~m}$ và dài $20 \mathrm{~m}$ ), như vậy sẽ không có yếu tố cá biệt, giá "đấu giá" sẽ được sử dụng như là "giá trị danh nghĩa" của thửa đất tại thời điểm nghiên cứu.

Giới hạn của nghiên cứu này chỉ tính đến ảnh hưởng của các yếu tố quy hoạch hạ tầng kỹ thuật như giao thông, ủy ban, trường học, bệnh viện, chợ, trung tâm thương mại, công viên, nhà hát.... được thực hiện ở cuối kỳ quy hoạch, mà chưa có điều kiện tính đến các yếu tố phát triển kinh tế kinh tế - xã hội khác, bởi không đủ các số liệu dự báo. Ước tính giá trị đất do ảnh hưởng của quy hoạch với điều kiện quy hoạch sẽ được triển khai, các đối tượng quy hoạch được triển khai đến đâu thì mô hình sẽ ước tính giá trị đất đến thời điểm đó.

\section{Phương pháp và dữ liệu nghiên cứu}

\subsection{Lụa chọn các yếu tố hình thành giá trị đất ở}

Có nhiều phương pháp phân loại các yếu tố hình thành giá trị đất [Nguyễn Phi Sơn. 2015], tuy nhiên, cách tiếp cận "Đất đai tọa lạc ở bất kỳ địa địa điểm nào trong một quốc gia đều chịu tác động của các nhóm yếu tố tự nhiên, kinh tế xã hội, môi trường và chính sách của quốc gia đó" là cách tiếp cận mang tính tổng hợp và phù hợp với mục tiêu ứng dụng mô hình thống kê không gian. Các yếu tố tác động theo cách phân loại này chi phối theo nhiều phương cách tác động, từ tổng thể đến chi tiết, từ gián tiếp đến trực tiếp, từ ngoại cảnh đến nội tại. Trên quan điểm này, các yếu tố hình thành giá trị đất được xem xét trong phạm vi rộng lớn hơn, làm cho cường độ tác động, phạm vi tác động, loại hình tác động sẽ được tính đến đầy đủ. Các yếu tố hình thành giá trị đất như sau:

Nhóm các yếu tố về tư nhiên và môi truờng: là tập hợp của một nhóm các yếu tố về mức độ ảnh hưởng của tính thuận lợi hay không thuận lợi, khả năng tiếp cận các dịch vụ xã hội, tiện nghi khu vực việc làm, hạ tầng kỹ thuật, địa thế khu vực, yếu tố vật lý của thửa đất...dựa trên quan điểm "càng gần càng tốt" đối với các yếu tố "tích cực" và "càng xa càng tốt" đối với các yếu tố "tiêu cực". Nhóm yếu tố này sẽ liên quan đến mạng lưới giao thông, khoảng cách đến các cơ quan có dịch vụ xã hội, dịch vụ công, liên quan đến chất lượng của môi trường sống (không khí, đất, nước, tiếng ồn), điều kiện kinh tế hay thu nhập của dân cư (tăng trưởng kinh tế, thu nhập đầu người), sự hoàn thiện của môi trường cảnh quan, "đẳng cấp" của khu vực, mức sống và mật độ dân số. Từ phân tích trên các yếu tố được đề xuất như sau: Độ dốc địa hình (Dh); Chất lượng môi trường không khí (Kk); Chất lượng môi trường nước $(\mathrm{CNu})$; Địa chất - thổ nhưỡng (Da); Điều kiện khí hậu (Kh); Khả năng cung cấp nước sạch $(\mathrm{Ns})$; Khoảng cách đến trung tâm đô thị Loại đặc biệt, loại I và loại II (KcDt1); Khoảng cách đến trung tâm đô thị Loại III và Loại IV $(\mathrm{KcDt} 2)$; Khoảng cách từ thửa đất đến UBND xã/phường (KcUB); Khoảng cách đến trụ sở công an huyện, tỉnh (KcCA); Khoảng cách từ thửa đất đến trường $\mathrm{TH}$ phổ thông gần nhất (KcTr); Khoảng cách từ thửa đất đến trường cao đẳng, đại học, dạy nghề cấp tỉnh $(\mathrm{KcDh})$; 
Khoảng cách từ thửa đất đến trung tâm y tế cấp huyện, tỉnh, các bệnh viện cấp trung ương. $(\mathrm{KcBv})$; Khoảng cách từ thửa đất đến chợ lớn $(\mathrm{KcCh})$; Khoảng cách từ thửa đất đến siêu thị, trung tâm thương mại lớn $(\mathrm{KcSt})$; Khoảng cách đến trung tâm văn hóa, nghệ thuật, bảo tàng, nhà hát, thể thao cấp huyện trở lên $(\mathrm{KcVh})$; Khoảng cách đến công viên, khu vui chơi liên hợp ngoài trời $(\mathrm{KcCv})$; Khoảng cách đến bến xe, bến tàu lớn $(\mathrm{KcBx})$; Khoảng cách đến điểm di tích lịch sử cấp tỉnh, Quốc gia (KcLs); Khoảng cách đến điểm du lịch nổi tiếng $(\mathrm{KcDl})$; Hạ tầng giao thông (Ht).

Nhóm các yếu tố về kinh tế - xã họi: là tập hợp các tác động của chỉ số kinh tế, gián tiếp ảnh hưởng đến việc hình thành giá trị đất. Môi trường kinh doanh và mức độ phát triển của các thành phần kinh tế, các ngành nghề kinh tế đã tạo động lực cho thị trường bất động sản phát triển. Mức độ đầu tư trong nước, đầu tư từ nước ngoài, tăng trưởng kinh tế đã làm cho thu nhập của xã hội tăng lên, sức hút của tăng dân số cơ học tạo ra sức ép đối với quỹ đất ở... là những yếu tố làm cho giá trị đất có sự khác biệt giữa các vùng, các địa phương. Từ phân tích trên các yếu tố đề xuất gồm: Tốc độ tăng trưởng GDP cấp huyện (GDP); Tốc độ tăng dân số tự nhiên (TDs).

- Các yếu tố về pháp lý liên quan đến bất động sản: là sự phù hợp của mục đích sử dụng đất với quy hoạch, chiến lược. Việc hạn chế trong xây dựng, hành lang an toàn các công trình... cũng có tác động đối với giá trị sử dụng của đất ở. Từ phân tích trên các yếu tố đề xuất gồm: Sự phù hợp với quy hoạch sử dụng đất ( $\mathrm{PhQh})$; Hạn chế xây dựng $(\mathrm{HcXd})$.

\subsection{Xây dưng vùng giá trị đất ở tại thời điểm đầu kỳ quy hoạch}

- Dũ liệu cần thu thập bao gồm: Giá đất của các thửa đất tiêu biểu được thu thập từ các dự án đấu giá quyền sử dụng đất của các huyện, thị, hoặc số liệu thực theo giá thị trường của các giao dịch. Các dữ liệu về kinh tế - xã hội từ niên giám thống kêvà báo cáo kinh tế xã hội của tỉnh; các dữ liệu bản đồ nền địa hình, giao thông, thủy hệ, địa giới hành chính được lấy từ cơ sở dữ liệu địa hình 1:50.000. Các số liệu về khoảng cách gần nhất từ thửa đất tiêu biểu đến các "yếu tố tác động dạng điểm - Điểm trung tâm" được thống kê dựa trên mạng lưới đường giao thông theo thuật toán tính khoảng cách gần nhất. Các yếu tố về môi trường, khí hậu, khả năng cung cấp nước sạch, các yếu tố kinh tế - xã hội, pháp lý được biểu thị bằng phương pháp nền chất lượng theo đơn vị hành chính cấp huyện/thị. Các lớp dữ liệu được xây dựng thống nhất trong cùng khung tham chiếu không gian VN2000, kinh tuyến trục theo tinh.

- Xây dưng hàm giá trị đất $(V)$ : Trong tổng số 25 yếu tố đã được chia thành 3 nhóm, trong đó 4 biến giả (biến nhị phân) và 21 biến thực. Như vậy tại mỗi thửa đất sẽ có các số liệu như: giá đất $(V)$; số liệu về 25 yếu tố hình thành giá trị đất $\left(n_{j}\right.$, $\left.e_{j}, l_{j}\right)$, sẽ được sử dụng để lập hàm hồi quy đa biến, trong đó $(V)$ là biến phụ thuộc và 25 biến độc lập. Chất lượng của hàm giá trị đất $(V)=f\left(n_{j}\right.$, $\left.e_{j}, l_{j}\right)$ được đánh giá bằng các chỉ số $r^{2}, f$, sig, theo thuật toán hồi quy.

- Xây dưng vùng giá trị đất toàn tỉnh: Sử dụng ArcGIS10.3 để tính khoảng cách từ tâm các thửa đất ở trên địa bàn tỉnh đến các "Điểm trung tâm”. Chồng xếp các lớp dữ liệu về môi trường, khí hậu, khả năng cung cấp nước sạch, các yếu tố kinh tế - xã hội, pháp lý và gán giá trị của mỗi thửa đất, thống kê các thuộc tính cho mỗi thửa đất. Tính giá trị đất cho các vị trí mắt lưới $500 \times 500 \mathrm{~m}$ của toàn bộ phạm vi đất ở bằng hàm giá trị đất ở trên. Chúng ta sẽ có một lớp dữ liệu về giá trị đất ở dạng vector có độ phân giải 500 x 500m phủ kín đất ở trên địa bàn toàn tỉnh. Từ đây có thể nội suy ra các vùng giá trị đất theo phân khoảng quy định.

\subsection{Thiết lập được vùng giá trị đất trong tuoong lai theo phương án quy hoạch}

Việc thiết lập vùng giá trị đất trong tương lai theo phương án quy hoạch được thực hiện qua các bước sau:

- Rà soát trên bản đồ quy hoạch sử dụng đất 
để chọn các yếu tố sẽ tham gia vào mô hình tính giá trị đất gồm: Lớp giao thông; Lớp công trình xây dựng (sân bay, bến cảng, ga tầu, trường học, bệnh viện, chợ lớn, ...); Lớp di tích, danh thắng; Lớp bãi thải, xử lý chất thải; Lớp công trình phúc lợi xã hội (nhà hát, công viên, khu giải trí phức hợp, ...); Lớp các cơ quan công quyền và dịch vụ công (UBND các cấp, Công an, ....). Các đối tượng mới sẽ được chuẩn hóa bổ sung vào các lớp dữ liệu tương ứng với các yếu tố hình thành nên giá trị đất.

- Từ bảng dữ liệu về mỗi Pixel, áp dụng hàm " $f$ " ở trên để tính $V_{j}$ cho từng Pixel $500 \times 500 \mathrm{~m}$. Tương tự, chúng ta sẽ có một lớp dữ liệu về giá trị đất ở dạng vector có độ phân giải 500 x 500m phủ kín toàn tỉnh cho thời điểm cuối kỳ kế hoạch sử dụng đất. Từ đây có thể nội suy ra các vùng giá trị đất theo phân khoảng quy định.

\subsection{Dụ̂ báo mức độ biến động giá trị đất}

Chồng xếp 2 lớp raster bản đồ giá trị đất tại 2 thời điểm, tính toán biến động giá trị đất dựa trên giá trị $\Delta=\left(V_{2}\right)-\left(V_{1}\right),\left(V_{2}\right.$ là giá trị đất ước tính tại thời điểm cuối kỳ quy hoạch, $V_{l}$ là giá trị đất tại thời điểm nghiên cứu), kết quả cho ra lớp raster dự báo biến động giá trị đất do quy hoạch.

\section{Thực nghiệm tại tỉnh Quảng Ninh}

\subsection{Xây dựng bản đồ vùng giá trị đất ở trên địa bàn tỉnh Quảng Ninh năm 2017}

- Thu thập các loại dữ liệu: Dữ liệu về địa hình, giao thông, đất đai, môi trường, vị trí các đối tượng trung tâm; số liệu về kinh tế xã hội được lấy theo niên giám thống kê tỉnh Quảng Ninh năm 2017, gán cho các đơn vị hành chính; thu thập các dự án đấu giá quyền sử dụng đất ở tại các huyện, thị trong tỉnh Quảng Ninh (có 12 dự án, trên 12 huyện thị đã thực hiện đấu giá trong năm 2017, mỗi dự án lấy 5 vị trí làm mẫu. Do số lượng các dự án đấu giá quyền sử dụng đất có rất ít, vì vậy ảnh hưởng đến chất lượng của mô hình tính toán). Vị trí các dự án đã có trong hệ tọa độ VN2000, kinh tuyến trục 107030'.

- Số liệu khoảng cách từ các thửa đất đấu giá đến các "Điểm trung tâm" được tính bằng ArcGIS10.3 theo phương pháp "khoảng cách gần nhất". Gán giá trị các lớp yếu tố dạng vùng (kinh tế - xã hội, địa hình, môi trường....) cho các thửa đất đấu giá.

- Tổng hợp thành bảng dữ liệu ThuaDat*.xls về 60 vị trí đất đã hoàn thành đấu giá quyền sử dụng đất, bao gồm 26 cột: 25 cột là các "Biến tự do" và 1 cột là "Biến phụ thuộc".

Qua đánh giá tương quan riêng của mỗi biến tự do và biến phụ thuộc, cho thấy có 8 yếu tố có mức độ tương quan với giá đất danh nghĩa thấp $\mathrm{r}^{2}<0,1$ gồm: độ dốc của khu vực; tốc độ tăng dần số tự nhiên; chất lượng môi trường không khí; khoảng cách đến điểm di tích lịch sử quốc gia; Sự phù hợp với quy hoạch sử dụng đất; Hạn chế xây dựng. Các yếu tố này đã được loại bỏ trước khi chạy mô hình tổng quát. Còn lại 17 yếu tố còn lại đều có mức độ tương quan trung bình trở lên (đánh giá bằng các chỉ số $\mathrm{r}^{2}$, sig., $\mathrm{F} \ldots$..), có nghĩa là giá trị đất có phụ thuộc vào sự thay đổi của 17 yếu tố còn lại. Tổng số biến - yếu tố hình thành giá trị đất, tham gia trong lập hàm hồi quy là 17 biến.

- Sử dụng SPSS để thiết lập hàm giá trị đất năm 2017 tỉnh Quảng Ninh có dạng:

$$
\mathrm{V}=-15123568,91+6114690,215^{*} \mathrm{GDP}+
$$

$17,847 * \mathrm{KcBv}+33,788 * \mathrm{KcBx}-2,423 * \mathrm{KcDh}-$ $17,647 * \mathrm{KcCv}-157,080 * \mathrm{KcDl}+12,971 * \mathrm{KcDt} 1$ $-61,870 * \mathrm{KcDt} 2+37,615 * \mathrm{KcTr}-1,928 * \mathrm{KcSt}+$ $148,285^{*} \mathrm{KcVh}+142,425 * \mathrm{KcCh}-$ $179,969 * \mathrm{KcUB}-4,582 * \mathrm{KcCA}+81178,853 * \mathrm{Ns}$ $-2280220,578 * \mathrm{Da}+1712,178 * \mathrm{Ht}$

Các chỉ số để đánh giá mức độ tương quan: Trị số $\mathrm{r}^{2}=0,611$, Sig. $<0.010, \mathrm{~F}>15$ có nghĩa là trong phương trình tuyến tính có quan hệ khá chặt chẽ giữa giá đất danh nghĩa và 17 yếu tố, các yếu tố này sẽ giải thích được gần $61,1 \%$ sự thay đổi của giá trị đất ở trên địa bàn tỉnh Quảng Ninh (mức độ tương quan này chưa cao do hạn chế về điều kiện thu thập số liệu tại địa phương). (Xem hinh 1) 


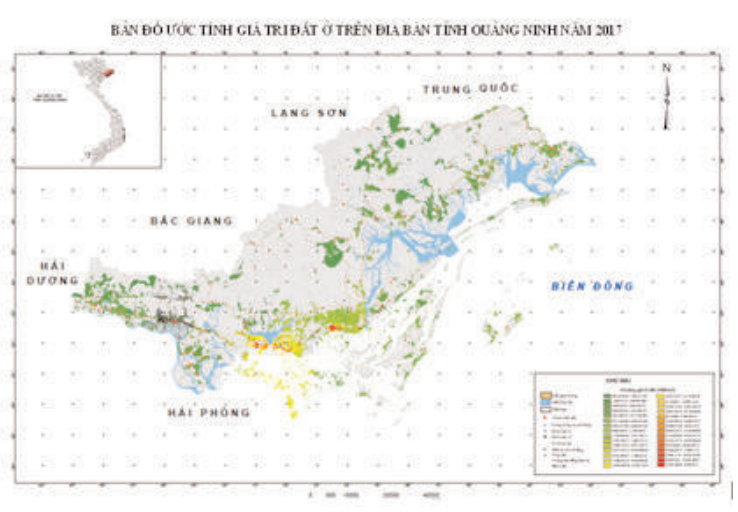

Hình 1: Bản đồ vớc tính giá trị đầt ỏ trên địa bàn tỉnh Quảng Ninh năm 2017

3.2. Chuẩn hóa dĩ liệu quy hoạch sử dụng đất tỉnh Quảng Ninh đến năm 2020

Bản đồ Quy hoạch SDĐ tỉnh Quảng Ninh đến năm 2020 đã được phê duyệt tại Quyết định số 1234/2016/QĐ-UBND ngày 22/12/2016. Trong nghiên cứu này lấy các yếu tố quy hoạch như: Giao thông; Lớp công trình xây dựng (sân bay, bến cảng, ga tầu, trường học, bệnh viện, chợ lớn, ...); Lớp di tích, danh thắng; Lớp bãi thải, xử lý chất thải; Lớp công trình phúc lợi xã hội (nhà hát, công viên, khu giải trí phức hợp, ...); Lớp các cơ quan công quyền và dịch vụ công (UBND các cấp, Công an, ...) sẽ được chuẩn hóa theo quy định.

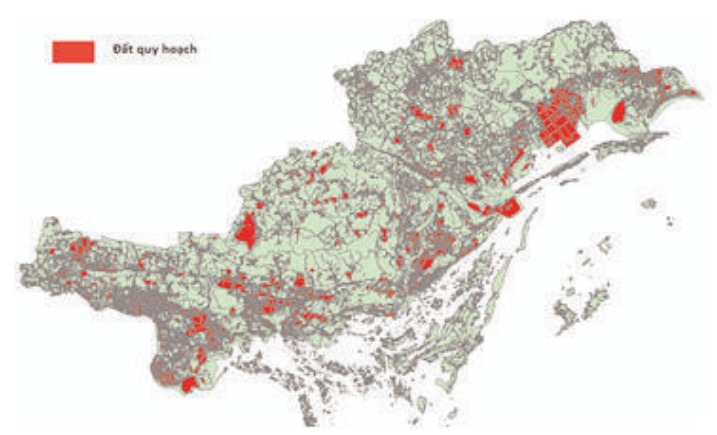

Hình 2: Lớp dũ liệu đất quy hoạch tỉnh Quảng Ninh năm 2020
3.3. Xây dụng bản đồ giá trị đất ở theo phương án quy hoạch sử dụng đất tỉnh Quảng Ninh đến năm 2020

Trên cơ sở các yếu tố của bản đồ quy hoạch sử dụng đất tỉnh Quảng Ninh năm 2020 tỷ lệ 1:100.000 sau khi chuẩn hóa theo quy định, với điều kiện giả thiết các phương án quy hoạch được thực hiện đầy đủ tại cuối kỳ. Cụ thể một số đối tượng trên quy hoạch mới như: Đường giao thông mới; Bến xe, bến tàu: Ga Hạ Long; Ga Yên Cư; Ga Cái Lân; Sân bay Vân Đồn. Trường Trung học phổ thông: 8 trường học ở các xã, phường: Đức Chính, Hoàng Quế, Quang Trung, Minh Thành, Hồng Hải, Đông Ngũ, Đồng Tâm, Đại Yên. Điểm du lịch nổi tiếng: Khu du lịch Trà Cồ, Móng Cái. Bệnh viện: Thêm 11 trung tâm y tế, bệnh viện trên địa bàn Uông Bí, Hạ Long; Các khu đô thị, ...

Sử dụng hàm giá đất (2) và bộ dữ liệu của bản đồ quy hoạch để tính $V_{2020}$ cho tất cả các Pixel $500 \times 500 \mathrm{~m}$ đất ở trên địa bàn tỉnh, từ đó nội suy bản đồ ước tính giá trị đất ở tỉnh Quảng Ninh năm 2020, như Hình 3:

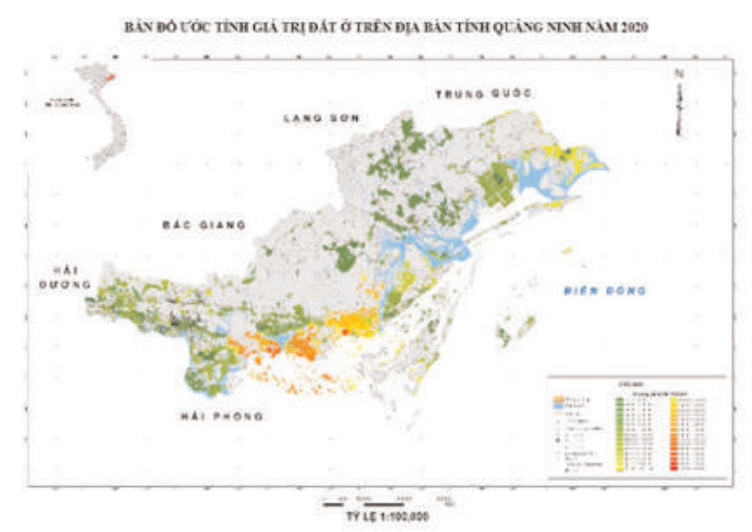

Hình 3: Bản đồ ước tính giá trị đất ở trên địa bàn tỉnh Quảng Ninh năm 2020 


\subsection{Dụ báo mức độ biến động giá trị đất giai đoạn tù̀ 2017 đến 2020 tỉnh Quảng Ninh}

Chồng xếp 2 lớp raster bản đồ giá trị đất năm 2020 và 2017, tính toán biến động giá trị đất dựa trên giá trị $\Delta=V_{2020}-V_{2017}$. Kết quả cho ra lớp raster dự báo biến động giá trị đất do quy hoạch được thể hiện trong hình 4 .

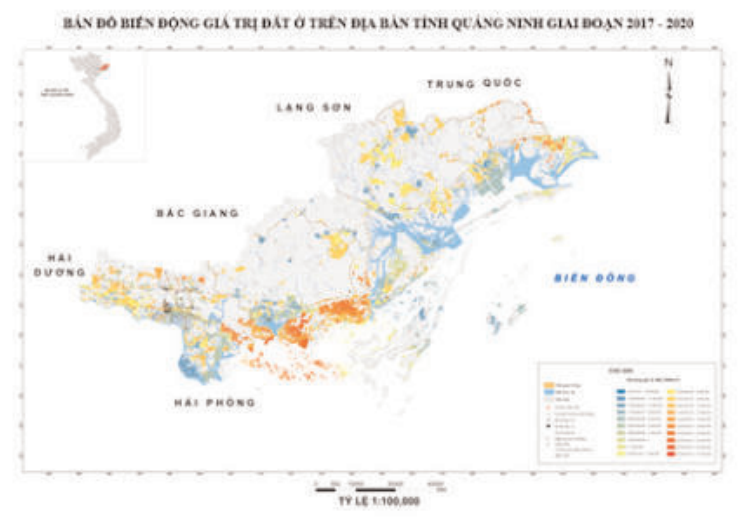

Hình 4: Bản đồ biến động giá trị đất ở trên địa bàn tỉnh Quảng Ninh giai đoạn 2017 - 2020

Theo kết quả tính biến động, giá trị đất đã thay đổi rất nhiều theo hướng ngày càng tăng lên. Điều này cũng hoàn toàn dễ hiểu khi Quảng Ninh có tốc độ đô thị hóa cao kéo theo kinh tế, hạ tầng giao thông và các dịch vụ phát triển rất nhanh. Do đó, giá đất trong tương lai tăng lên rất rõ ràng. Theo như dự báo đề tài đã tính toán được giá trị $\Delta$ cao nhất đạt 27,34 triệu/ $\mathrm{m}^{2}$ ở khu vực thành phố Hạ Long, khu vực Vân Đồn. Nguyên do là vì thành phố Hạ Long và Vân Đồn là trọng điểm phát triển của toàn tỉnh, đang đẩy mạnh phát triển du lịch, kinh tế và ngày càng có nhiều dự án phát triển đô thị, hạ tầng giao thông ở đây nên dự tính giá đất tăng lên mạnh mẽ.

Tuy nhiên, song song với quá trình đô thị hóa cũng là nguy cơ gây ô nhiễm môi trường và đặc biệt là rác thải khu đô thị. Ngay khu vực xã Thống Nhất, huyện Hoành Bồ giáp thành phố Hạ Long được quy hoạch một khu vực bãi rác rất lớn. Vì vậy, giá đất khu vực này giảm mạnh (giá trị $\Delta$ nhỏ nhất là $-18,32$ triệu $/ \mathrm{m}^{2}$ ).

\section{Kết luận}

Bài báo đã đề cập đến cách tiếp cận khi xây dựng bản đồ vùng giá trị đất theo khái niệm "giá trị đất danh nghĩa", đây là phương pháp hình thành dựa trên lý thuyết "hồi quy Hedonic". Từ hàm giá trị đất xây dựng được bề mặt giá trị và đó là cơ sở cho việc thành lập bản đồ phân vùng giá trị đất. Từ quy trình thành lập bản đồ vùng giá trị đất, bài báo đã lồng ghép dữ liệu quy hoạch sử dụng đất làm cơ sở để xây dựng bản đồ vùng giá trị đất năm 2020. So sánh 2 bản đồ chúng ta có được mức độ biến động giá trị đất do quy hoạch. Vùng giá trị đất có nhiều ứng dụng trong quản lý, quy hoạch, phát triển kinh tế, đầu tư và đánh giá tiềm năng, đặc biệt là ứng dụng trong định giá đất hàng loạt. Ước tính biến động giá trị đất ở những thời điểm trong tương lai theo mô hình của bài báo này có thể tự động và nhanh chóng đưa ra kết quả, góp phần quan trọng cho các cơ quan quản lý nhà nước nắm bắt được $\mathrm{xu}$ thế biến động của giá trị đất từng vùng do tác động của yếu tố quy hoạch. $\bigcirc$

\section{Tài liệu tham khảo}

[1]. Abdul Hamid. "Combiming geographic information systems and regression models to generate locational value residual surfaces in the assessment of residential property values". Universiti Teknologi Malaysia. Pacific Rim Property Research Journal, Vol 13, No 1. PP 3562. 2008

[2]. Alicia E. Porcar Lahoz. "An analysis of how geographical factors affect real estate prices"- Master's of Science Thesis in Geoinformatics - School of Architecture and the Built Environment Royal Institute of Technology (KTH) 10044 Stockholm, Sweden. 2007.

[3]. A. Myrick Freeman III. "The Measurement of Environmental and Resource 
Values: Theory and Methods", Second Edition, Washington: Resources for the Future, 2003

[4]. Chin Chui Vui. "Using geographical information system - Multiple regression analysis - Genetated location value response surface approach to model locational fator in the prediction of residential property values". Universiti Teknologi Malaysia. 2006.

[5]. Haripriya Gundimeda. "Hedonic price method - A Concept Note". Madras School of Economics Chennai. 2005.

[6]. Marko Kryvobokov. "Mass valuation of urban land in Ukraine from normative to a market-based approach". School of Architecture and the Built Environment Royal Institute of Technology (KTH) 10044 Stockholm, Sweden. 2006.

[7]. Mehmet Topcu, Ayse Sema Kubat. "The Analysis of Urban Features that Affect Land Values in Residential Areas". Selcuk University, Faculty of Engineering \& Architecture, Department of Urban and Regional Planning, Konya, Turkey. 2009.
[8]. Ping Ai. "Residental Land value modelling case study of Hankou”, China. 2005.

[9]. Roberto A. Figueroa. "Modeling the Value of Location in Regina Using GIS and Spatial Autocorrelation Statistics". Assessment Journal; Nov/Dec 1999; 6, 6; ABI/INFORM Global PP.29.

[10]. Vevin S. Ardiwijaya. "Land value zone automation for land market information". Bogor Agricultural University. Jakarta, December/2006.

[11]. Hoàng Hữu Phê và Patrick Wakely - Vị thế, chất lượng và sự lựa chọn khác: Tiến tới một Lí thuyết mới về Vị trí Dân cư Đô thị, Tạp chí Đô thị học (Urban Studies) xuất bản tại Vương quốc Anh, Vol. 37, No. 1, January 2000.

[12]. Nguyễn Phi Sơn và nnk. "Nghiên cứu phương pháp xây dựng bản đồ vùng giá trị đất khu vực đất phi nông nghiệp tại đô thị bằng mô hình thống kê và GIS". Đề tài khoa học công nghệ cấp Bộ. 2015.O

\section{Summary}

\section{Estimating the impact of land use planning on land value, test for residential area in Quang Ninh province}

Nguyen Phi Son, Nguyen Thanh Thuy, Nguyen Thi Thanh Huong

Institute of Geodesy and Cartography

The paper mentions the method of establishing land value maps based on Hedonic theory and GIS technology, from which it is possible to predict the fluctuation of land value when changing the influencing factors. Land use planning is one of the factors affecting future land values. Predicting the impact of land use planning on the trend of land value changes is necessary, computer valuation methods based on computer technology and GIS can solve this problem. In the article, we have experimented for the land area in Quang Ninh province. $O$ 